\title{
Effects of Annealing Temperature on Raman Scattering and Electrical Properties of Te-Doped Nanostructured Black Silicon
}

\author{
Yuanjie Su${ }^{1}$, Ting Zhang ${ }^{1}$, Peng Zhang ${ }^{1}$, Jing Jiang ${ }^{1}$, Zhanfei Xiao ${ }^{1}$, Shibin $\mathrm{Li}^{1}$, Zhiming Wu ${ }^{1} \&$ Yadong Jiang ${ }^{1}$ \\ ${ }^{1}$ State Key Laboratory of Electronic Thin Films and Integrated Devices, School of Optoelectronic Information, \\ University of Electronic Science and Technology of China (UESTC), Chengdu, P. R. China \\ Correspondence: Shibin Li, State Key Laboratory of Electronic Thin Films and Integrated Devices, School of \\ Optoelectronic Information, University of Electronic Science and Technology of China (UESTC), Chengdu \\ 610054, P. R. China. Tel: 86-288-320-8959. E-mail: shibinli@uestc.edu.cn
}

Received: October 10, 2012 Accepted: October 25, 2012 Online Published: November 6, 2012

doi:10.5539/jmsr.v2n1p34 URL: http://dx.doi.org/10.5539/jmsr.v2n1p34

\begin{abstract}
In this paper, the influence of annealing temperature on Raman scattering and transport properties of Te-doped nanostructured black silicon has been studied. We prepared the black silicon samples by wet etching, i.e. alkaline etching and metal assisted etching. The nanopores on the surface of black silicon were produced by metal assisted etching. The black silicon samples were annealed at different temperature of $600^{\circ} \mathrm{C}, 700^{\circ} \mathrm{C}$, and $800^{\circ} \mathrm{C}$ According to the Raman scattering results, the peak intensity of $\mathrm{Si}$ increases with the increase of annealing temperature. However, the full width at half maximum (FWHM) is inversely proportion to the annealing temperature. Thermal annealing removes the Raman peak of amorphous Si at $480 \mathrm{~cm}^{-1}$. In term of Te dopant atoms, the peak intensities of annealed samples are much lower than that of unannealed one. Subsequent Hall Effect measurement shows that annealing treatment improves electronic transport properties of Te-doped nanostructured black silicon.
\end{abstract}

Keywords: Raman scattering, annealing, nanostructured black silicon, Hall Effect measurement

\section{Introduction}

Nanostructured semiconductor owns great potential for achieving optical communication (Myers et al., 2006) and sensor net. Due to high absorptance ( $>90 \%$ ) (Crouch et al., 2004) and wide absorption spectrum ranging from ultraviolet (UV) to near infrared (NIR) (Younkin et al., 2003; Das et al., 2012; Sheehy et al., 2005), nanostructured black silicon is an ideal material to fabricate sensitive photodetectors, solar cell (Yuan et al., 2009; Koynov et al., 2006), biochemical sensor (Noval et al., 2011), display devices (Treado et al., 1994; Tezcan et al., 2003; Fixe et al., 2004), gas sensor (Trakhtenberg et al., 2012). Nanostructure of the black silicon has been the focus of intense interest in recent years due to their extensive device application (Li et al., 2011; Li et al., 2008; Kumar et al., 2012). There are mainly four ways to fabricate black silicon-femtosecond laser (Wu et al., 2001; Kabashin et al., 2010; Othonos et al., 2009), deep reactive ion etch (DRIE) (Fischer et al., 2009), metal assisted wet etching (Branz et al., 2009), and electrochemical etching (Ma et al., 2006). Eric Mazur (Crouch et al., 2004) microstructured silicon surfaces with femtosecond laser irradiation in the presence of $\mathrm{SF}_{6}$. The sulfur element was introduced into silicon in the ablation process so as to introduce states into the band gap of crystalline silicon and thus enhance the below-band gap absorption. For this reason, silicon doped with Te was chosen for the fabrication of black silicon. In this work, the nanostructured black silicon was fabricated by wet etching method. The single crystal silicon was immersed in a solution containing hydrofluoric acid (HF) and hydrogen peroxide $\left(\mathrm{H}_{2} \mathrm{O}_{2}\right)$. The crystal silicon is etched in the presence of noble metal catalysts (Nishioka et al., 2008).

Thermal annealing is widely used in modern silicon device manufacturing technology. It is a thermal processing technique with isothermal annealing behavior and leads to a uniform lateral and transverse heating profile throughout a wide area.

In this work, the effects of annealing temperature on Te diffusion and electrical properties of nanostructured black silicon photodetector was investigated by Raman scattering and Hall Effect measurement. Raman scattering provides a fast and non-destructive way to determine the degree of crystallization and tensile/compressive stress from the peak shape and peak position (Choi et al., 1999; Nesheva et al., 2002). Furthermore, Subsequent Hall Effect measurement shows that annealing at different temperature has a 
significant influence on the electronic properties of Te-doped nanostructured black silicon, such as mobility, conductivity, and sheet concentration.

\section{Experiment}

Figure 1 shows the fabrication process of black silicon by wet etching. Te doped silicon was obtained by ion implantation of Te into single crystal silicon (100) wafer $\left(\mathrm{R}=8 \Omega / \mathrm{cm}^{2}\right)$ at applied voltage of $40 \mathrm{kV}$, resulting in a bulk concentration of $1 \times 10^{16} \mathrm{~cm}^{-3}$. According to the TRIM98 ion implantation simulation, the depth of Te dopant atoms is about $74.2 \mathrm{~nm}$ with a peak density at $27.8 \mathrm{~nm}$. As shown in Figure 1, firstly, $\mathrm{Si}_{3} \mathrm{~N}_{4}$ pattern was obtained on the surface of silicon by PECVD and lithography. Secondly, the Te-doped $\mathrm{Si}$ wafer padded by $\mathrm{Si}_{3} \mathrm{~N}_{4}$ as mask was etched by alkaline solution $(5 \mathrm{~g} \mathrm{KOH}+10 \mathrm{~mL}$ deionized water $+15 \mathrm{~mL}$ isopropanol) in the Constant Temperature Water-bathing at temperature of $50^{\circ} \mathrm{C}$, forming the micro-column columns, as shown in Figure 1(b). The Te-doped Si wafer was immersed in $\mathrm{HAuCI}_{4}, \mathrm{H}_{2} \mathrm{O}_{2}$, $\mathrm{HF}$ (Volume rate=1: 7: 5) mixed reactive solution for 8 $\mathrm{min}$ at room temperature. As shown in Figure 1(c), the Au nanoparticles from $\mathrm{HAuCI}_{4}$ facilitate the etching in $\mathrm{HF}$ and $\mathrm{H}_{2} \mathrm{O}_{2}$ (Li et al., 2000) and fabricate the porous structure on the surface. Consequently, black silicon material is produced. Figure 2 presents the SEM images of nanostructure achieved by Au assisted $\mathrm{HF} / \mathrm{H}_{2} \mathrm{O}_{2}$ etching. Figure 2(a) and Figure 2(b) exhibit the top view and cross-section view of nanopores on the surface of black silicon, respectively. The diameters of the nanopores range from $60 \mathrm{~nm}$ to $100 \mathrm{~nm}$ and the depth of etched nanopores is larger than $500 \mathrm{~nm}$. The high aspect ratio of these nanopores enhances the absorption of black silicon remarkably.

After fabrication, three samples were quickly annealed for 1 hour at pressure of $3.6 \times 10^{-3} \mathrm{~Pa}$ by furnace annealing at temperature of $600^{\circ} \mathrm{C}, 700^{\circ} \mathrm{C}$, and $800^{\circ} \mathrm{C}$, respectively. An unannealed sample was used as control sample in our experiment.

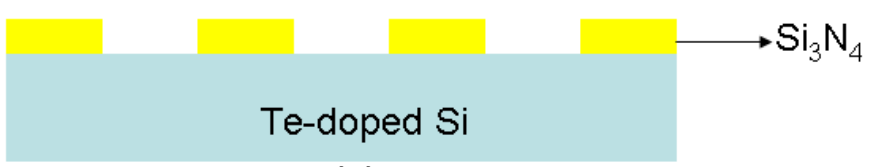

(a)

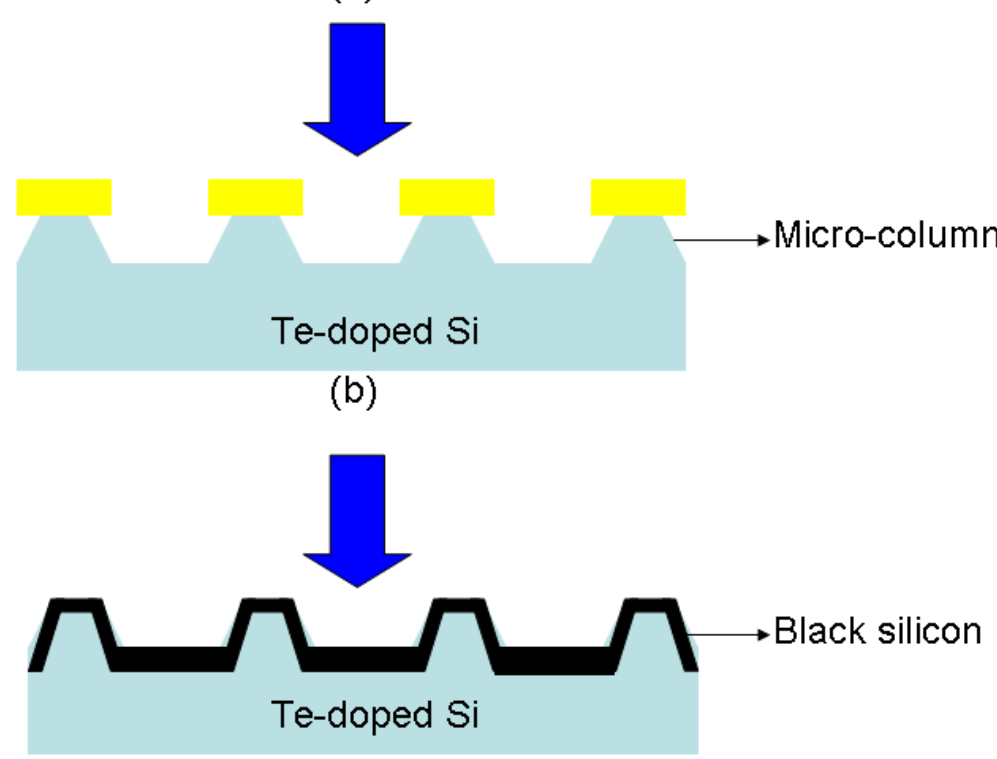

(c)

Figure 1. Schematic diagram of fabrication of Te-doped nanostructured black silicon: (a) Te-doped Single crystalline silicon padded with $\mathrm{Si}_{3} \mathrm{~N}_{4}$ as mask; (b) Micro-column structure after anisotropic $\mathrm{KOH}$ etching; (c) nanopores achieved by metal-assisted wet etching 


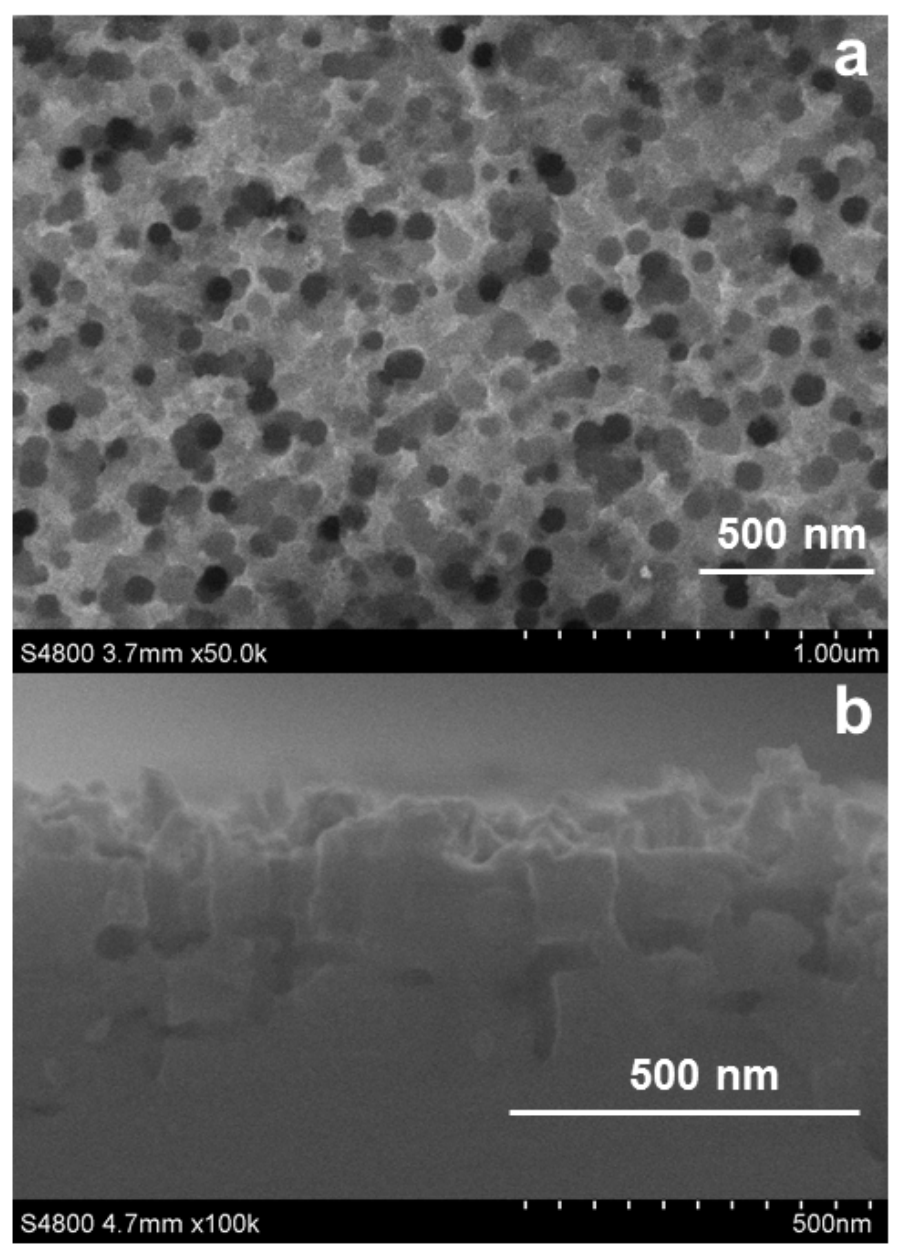

Figure 2. SEM images of nanostructure after $\mathrm{HF} / \mathrm{H}_{2} \mathrm{O}_{2}$ etching: (a) top view of nanopores; (b) the cross-section view of nanopores

The influence of annealing temperature on the crystal and chemical properties of the nanostructured black silicon layer were analyzed with JY-HR800 Raman scattering system. In Raman scattering measurement, the wavelength of laser is $532 \mathrm{~nm}$ and power is $1 \mathrm{~mW}$. Meanwhile, the electrical properties of unannealed and annealed black silicon samples were characterized by Hall Effect measurement.

\section{Results and Discussion}

\subsection{Raman Scattering Results of Annealed Black Silicon}

Figure 3 shows the room temperature Raman scattering spectra of the samples after thermal annealing treatment at different temperatures. As exhibited in Figure 3, the Si nanocrystal Raman peaks are observed in $521-522$ $\mathrm{cm}^{-1}$ range for all samples. The intensity is proportional to the annealing temperature. The Raman spectrum of nanocrystals on the surface of black silicon at different annealing temperature is asymmetric due to photon confinement.

Table 1 exhibits that the measured normalized Raman intensity $\left(I_{R}\right)$, peak position $(\omega)$, FWHM, and average nanocrystal size $(d)$, of black silicon for different annealing temperature $\left(T_{a}\right)$, in Figure 3. It is noteworthy that the calculated Raman line shape depends very critically on the size of the nanocrystal. The mean size of nanocrystal measured by high resolution electron microscopy (HREM) increases with increasing annealing temperature. This is attributed to that the higher annealing temperature causes less grain boundaries in the film, and the film will become more crystalline. The similar peak position for all sample suggests that when nanocrystal semiconductor were etched to a reasonable size (Choi et al., 1999), varying annealing temperature does not shift the peak position and the peak position should get closer to that of the bulk Si value of $521 \mathrm{~cm}^{-1}$. 
Table 1. Measured Raman peak positions $\omega$, FWHMs, mean sizes of nanocrystallites, $d$, and normalized intensities, $I_{R, \text {, a }}$ at different annealing temperature

\begin{tabular}{ccccc}
\hline$T_{a}\left({ }^{\circ} \mathrm{C}\right)$ & $\omega\left(\mathrm{cm}^{-1}\right)$ & $I_{R}(\%)$ & FWHM $\left(\mathrm{cm}^{-1}\right)$ & $d(\mathrm{~nm})$ \\
\hline Unannealed & 521.3 & 52.6 & 4.4 & 3.2 \\
600 & 521.3 & 53.2 & 3.4 & 3.6 \\
700 & 521.3 & 95.3 & 2.9 & 3.9 \\
800 & 521.3 & 100 & 2.1 & 4.5 \\
\hline
\end{tabular}

In Figure 3, the first peak intensity of $\mathrm{Si}$, at the wave number of $521.3 \mathrm{~cm}^{-1}$, increases proportionally to annealing temperature. The peak intensity of Si of annealed samples is higher than that of unannealed one. This is due to that high temperature thermal annealing was reported to be able to release the stress and decrease the structure faults (Zacharias et al., 1999). The vacancies near the film-substrate interface appear restructured after annealing treatment. It is possibly influenced by growth defects near the interface. However, the defects in the nanostructured black silicon are partially removed in the deeper of film (Reurings et al., 2010). In addition, the Te dopant atoms were forced to diffuse into deeper of silicon film in the annealing process, which accelerates the Raman scattering efficiency between Si atoms and incident light on the surface of black silicon. For these two reasons, the Raman intensity of $\mathrm{Si}$ at $521.3 \mathrm{~cm}^{-1}$ increases with increasing annealing temperature. On the other hand, the full width at half maximum (FWHM) of samples annealed at $600^{\circ} \mathrm{C}, 700^{\circ} \mathrm{C}$, and $800^{\circ} \mathrm{C}$ is $3.4 \mathrm{~cm}^{-1}, 2.9$ $\mathrm{cm}^{-1}$, and $2.1 \mathrm{~cm}^{-1}$, respectively, as indicated in Table 1. However, the FWHM of unannealed sample is $4.4 \mathrm{~cm}^{-1}$. The decrease of FWHM results from the thermal annealing process which increases the crystallinity of black silicon.

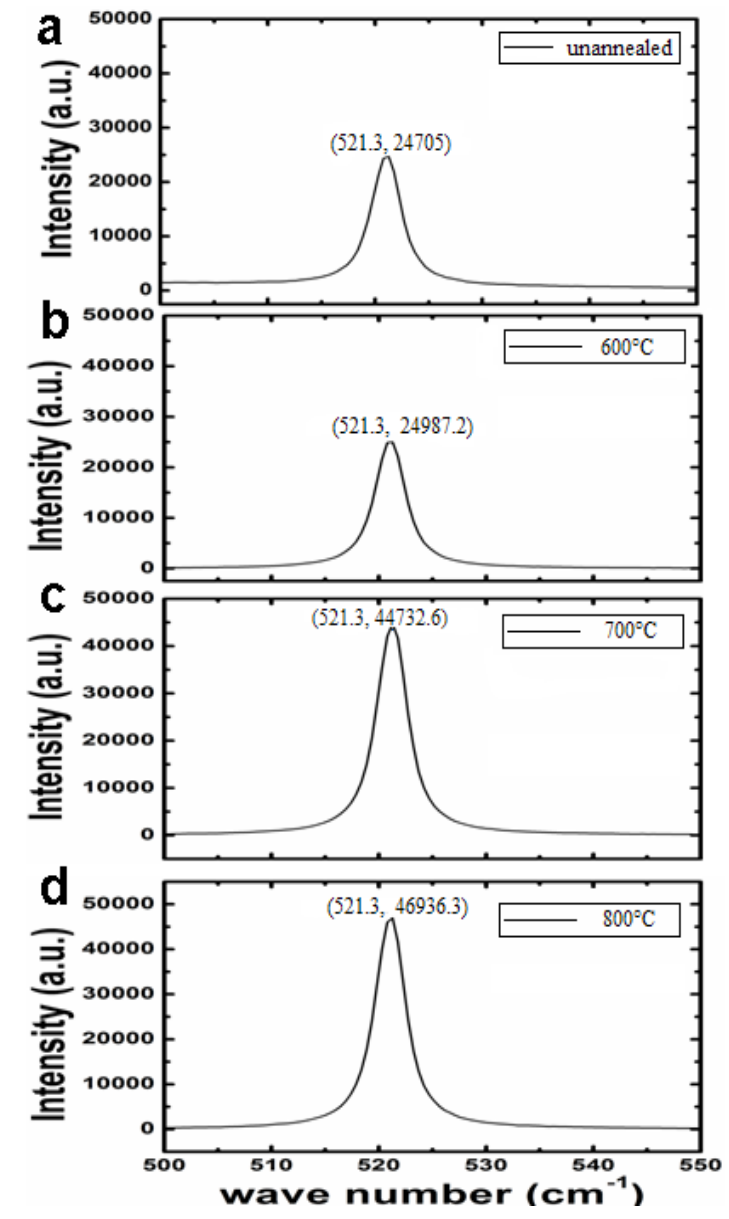

Figure 3. Raman scattering results of Te-doped nanostructured black silicon annealed at different temperature: (a) unannealed; (b) $600^{\circ} \mathrm{C}$; (c) $700^{\circ} \mathrm{C}$; (d) $800^{\circ} \mathrm{C}$ 
Since the strong Raman peak from the crystalline Si substrate masked the peak of ion implanted Te, the large Si peak intensity was ignored in order to observe signal from Te in the low intensity range as shown in Figure 4. The Raman peaks of Te doped black silicon are presented at the wave numbers of $123 \mathrm{~cm}^{-1}$ and $143 \mathrm{~cm}^{-1}$. It is worthwhile to note that the peak intensities of annealed samples are much lower than that of the control sample. However, as for the annealed samples, the intensities at these two wave numbers are enhanced by increasing the annealing temperature. This is mainly ascribed to that annealing treatment boosts the diffusion of ion implanted Te atoms deeper into the nanostructured black silicon layer and thus reduces the sheet concentration of Te atoms at relative low temperature. Furthermore, the lower annealing temperature process does not provide sufficient energy to remove defects or vacancies. For these two reasons above, peak intensities of Te for the annealed samples are low. Nevertheless, as the annealing temperature increases, the point defects surrounding Te atom induced by ion-implantation were eliminated during the thermal process. Due to the decreasing concentration of defects, the Raman scattering efficiency between Te atom and incident light was enhanced, leading to increase of Raman peak intensity of Te for the annealed samples.

As shown from Figure 4, a Raman peak at the lower frequency side of Si peak appears at $477 \mathrm{~cm}^{-1}$. It was only observed for the unannealed sample. Its FWHM is larger than that of the Si peak at $521 \mathrm{~cm}^{-1}$ which is similar to the characterized scattering band of amorphous Si at $480 \mathrm{~cm}^{-1}$. However, for the annealed samples, there is no peak observed at the wave number from $470 \mathrm{~cm}^{-1}$ to $480 \mathrm{~cm}^{-1}$ in Figure 4. It implies that the ion implantation and sequent wet etching introduces lattice defects, dislocations and vacancies in the nanostructured black silicon. The high temperature annealing process is able to restructure the vacancies near the black silicon-single crystal silicon interface and remove the ion implantation induced defects. The elimination of lattice defects, dislocation and vacancies decreases the amount of amorphous $\mathrm{Si}$ in the film and therefore reduces Raman scattering intensity at the amorphous Si peak of $480 \mathrm{~cm}^{-1}$.



Figure 4. Comparison of Raman scattering results under different annealing temperature

\subsection{Hall Effect Measurement of Annealed Black Silicon}

Table 2 shows the electric properties of nanostructured black silicon samples by Hall Effect measurement. The sign of Hall voltage is positive. The majority carriers in the nanoporous layer are holes. The intensity of magnetic field is $0.36 \mathrm{~T}$ in the Hall effect measurement. In Table $2, \mathrm{~N}_{\mathrm{b}}$ is carrier concentration, $\mu$ is Mobility, $\rho$ is Resistivity, and $\sigma$ is Conductivity for nanopores, respectively.

In Table 2, the mobilities of the annealed samples are much larger than the one without annealing. The highest mobility value is $3.6 \times 10^{4} \mathrm{~cm}^{2} \mathrm{~V}^{-1} \mathrm{~s}^{-1}$ at the temperature of $700^{\circ} \mathrm{C}$. This is mainly attributed to the thermal treatment process reduces tensile stress and point defects on Si nanocrystals. And thus, the lowest concentrations of deactivating defects and limitation of the formation of point defects are produced by migration process during the cooling down (Gaiduk et al., 2003). Elimination of deactivating defects and point defects decreases the scattering efficiency of carriers and thus improves the mobility in the nanostructured black silicon. On the other hand, due to the annealing process accerlerates the Te dopants diffusing into deeper of black silicon, the higher 
concentration of Te atoms will lower the drift speed of carriers under electric field. For this reason, the mobility at $800^{\circ} \mathrm{C}$ is lower than that of sample annealed at $700^{\circ} \mathrm{C}$. Since the high temperature annealing in vacuum accelerates the diffusion of Te dopant and motivates the doped atoms diffuse deeper into the black silicon, the number of donor carriers contributed by ion implanted Te atoms is enhanced. And then, the additional electrons from dopant atoms is released to enhance the free-carrier concentration (Carey et al., 2005). In terms of bulk concentration indicated in Table 2, the carrier concentration of black silicon sample annealed at $600^{\circ} \mathrm{C} 700^{\circ} \mathrm{C}$, and $800^{\circ} \mathrm{C}$ is $8.7 \times 10^{14} \mathrm{~cm}^{-3}, 1.1 \times 10^{15} \mathrm{~cm}^{-3}$, and $3.8 \times 10^{16} \mathrm{~cm}^{-3}$, respectively. However, the carrier concentration for unannealed sample is $2.8 \times 10^{14} \mathrm{~cm}^{-3}$.

With regards to the conductivity, due to the increase of mobility and bulk concentration upon annealing temperature, the conductivity increases proportionally to the annealing temperature significantly. The conductivity of control sample is only $5.8 \times 10^{-3} \Omega^{-1}$. However, the conductivities of annealed ones are at least one order of magnitude greater than the one without annealing.

Table 2. Hall Effect results of black silicon samples annealed at $600^{\circ} \mathrm{C}, 700^{\circ} \mathrm{C}, 800^{\circ} \mathrm{C}$, and without annealing, respectively

\begin{tabular}{ccccc}
\hline $\begin{array}{c}T_{a} \\
\left({ }^{\circ} \mathrm{C}\right)\end{array}$ & $\begin{array}{c}\mathrm{N}_{\mathrm{b}} \\
\left(\mathrm{cm}^{-3}\right)\end{array}$ & $\begin{array}{c}\mu \\
\left(\mathrm{cm}^{2} / \mathrm{Vs}\right)\end{array}$ & $\begin{array}{c}\rho \\
(\Omega \mathrm{cm})\end{array}$ & $\begin{array}{c}\sigma \\
(1 / \Omega \mathrm{cm})\end{array}$ \\
\hline unanealed & $2.8 \times 10^{14}$ & $1.3 \times 10^{2}$ & $1.7 \times 10^{2}$ & $5.8 \times 10^{-3}$ \\
600 & $8.7 \times 10^{14}$ & $8.4 \times 10^{2}$ & $8.3 \times 10^{0}$ & $1.2 \times 10^{-1}$ \\
700 & $1.1 \times 10^{15}$ & $3.6 \times 10^{4}$ & $1.6 \times 10^{-1}$ & $6.3 \times 10^{0}$ \\
800 & $3.8 \times 10^{16}$ & $4.1 \times 10^{3}$ & $4.0 \times 10^{-2}$ & $2.5 \times 10^{1}$ \\
\hline
\end{tabular}

\section{Conclusion}

The temperature of annealing is a key factor that affects shape and intensity of Raman spectroscopy of Te-doped nanostructured black silicon. According to the Raman scattering measurement, the Raman peak intensity of Si at $521.3 \mathrm{~cm}^{-1}$ upgrades with increasing annealing temperature significantly. However, the FWHM of annealed sample at Si peak is lower than that of unannealed one and decreases with increase of annealing temperature. Thermal annealing increases the crystallinity of black silicon and reduces the concentration of point defects and vacancies. Therefore, it is demonstrated the disappearance of amorphous Si peak at $477 \mathrm{~cm}^{-1}$ caused by heat treatment. The Raman scattering intensity of Te increases with increasing annealing temperature but is smaller than that of unannealed sample. Hall effect measurement indicates that thermal annealing process boosts the dopant diffusion and electrical properties of nanostructured black silicon material. The electrical properties, such as mobility, resistivity, carrier concentration, were changed by orders of magnitude during thermal annealing process because the stress and point defects in the nanostructured black silicon were eliminated.

\section{Acknowledgements}

This work was partially supported by National Science Foundation of China via grant No. 61101029. The author would like to thank Lei Yu and Xuehui Wang for their help in lithography and Hall effect measurement, and State Key Laboratory of Electronic Thin Films and Integrated Devices in China, for the help and equipment support.

\section{References}

Branz, H. M., Yost, V. E., Ward, S., Jones, K. M., To, B., \& Stradins, P. (2009). Nanostructured black silicon and the optical reflectance of graded-density surfaces. Appl. Phys. Lett., 94, 231121. http://dx.doi.org/10.1063/1.3152244

Carey, J. E., Crouch, C. H., Shen, M., \& Mazur, E. (2005). Visible and near-infrared responsivity of femtosecond-laser microstructured silicon photodiodes. Optics Letters, 30, 1773-1775. http://dx.doi.org/10.1364/OL.30.001773

Choi, W. K., Ng, V., Ng, S. P., Thio, H. H., Shen, Z. X., \& Li, W. S. (1999). Raman characterization of germanium nanocrystals in amorphous silicon oxide films synthesized by rapid thermal annealing. J. Appl. Phys., 86, 1398-1403. http://dx.doi.org/10.1063/1.370901 
Crouch, C. H., Carey. J. E., Shen. M., Mazur, E., \& Genin, F. Y. (2004). Infrared absorption by sulfur-doped silicon formed by femtosecond laser irradiation. Appl. Phys. A, 79, 1635-1641. http://dx.doi.org/10.1007/s00339-004-2676-0

Das, C. K., Bhattacharya, P., \& Kalra, S. S. (2012). Graphene and MWCNT: Potential Candidate for Microwave Absorbing Materials. Journal of Materials Science Research, 1(2), 126-132. http://dx.doi.org/10.5539/jmsr.v1n2p126

Fischer, C., Menezes, J. W., Moshkalev, S. A., Verissimo, C., Vaz, A. R., \& Swart, J. W. (2009). Fabrication of high-aspect ratio silicon nanopillars and nanocones using deep reactive ion etching. J. Vac. Sci. Technol. B, 27, 2732-2736. http://dx.doi.org/10.1116/1.3246359

Fixe, F., Chu, V., Prazeres, D. M. F., \& Condel, J. P. (2004). An on-chip thin film photodetector for the quantification of DNA probes and targets in microarrays. Nucleic Acids Res, 32, e70. http://dx.doi.org/10.1093/nar/gnh066

Gaiduk, P. I., Hansen, J. L., Larsen, A. N., \& Steinman, E. A. (2003). Nanovoids in MBE-grown SiGe alloys implanted in situ with Ge ${ }^{+}$ions. Phys. Rev. B, 67, 235310. http://dx.doi.org/10.1103/PhysRevB.67.235310

Kabashin, A. V., Delaporte, Ph., Pereira. A., Grojo, D., Torres, R., Sarnet, Th., \& Sentis, M. (2010). Nanofabrication with Pulsed Lasers. Nanoscale Res Lett, 5, 454-463. http://dx.doi.org/10.1007/s11671-010-9543-z

Koynov, S., Brandt, M. S., \& Stutzmann, Martin. (2006). Black nonreflecting silicon surfaces for solar cells. Appl. Phys. Lett., 88, 203107. http://dx.doi.org/10.1063/1.2204573

Kumar, R., Prakash, R., Alphonsa, J., Jain, J., Pareek, A., Rayjada Raole, P. M., \& Mukherjee, S. (2012). Impact of Forging Conditions on Plasma Nitrided Hot-forging Dies and Punches. Journal of Materials Science Research, 1(4), 11-18. http://dx.doi.org/ 10.5539/jmsr.v1n4p11

Li, S. B., Jiang, Y. D., Wu, Z. M., Wu, J., Ying, Z. H., Wang, Z. M., ... Salamo, G. (2011). Origins of $1 / f$ noise in nanostructure inclusion polymorphous silicon films. Nanoscale Res Lett, 6, 281. http://dx.doi.org/10.1186/1556-276X-6-281

Li, S. B., Wu, Z. M, Jiang, Y. D., Li, W., Liao, N. M., \& Yu, J. S. (2008). Structure and $1 / f$ noise of boron $\begin{array}{llll}\text { doped polymorphous silicon films. Nanotechnology, } & 19, \quad 085706 .\end{array}$ http://dx.doi.org/10.1088/0957-4484/19/8/085706

Li, X., \& Bohn, P. W. (2000). Metal-assisted chemical etching in $\mathrm{HF} / \mathrm{H}_{2} \mathrm{O}_{2}$ produces porous silicon. Appl. Phys. Lett., 77, 2572-2574. http://dx.doi.org/10.1063/1.1319191

Ma, L. L., Zhou, Y. C., Jiang, N., Lu, X., Shao. J., Lu, W., ... Hou, X. Y. (2006). Wide-band "black silicon" based on porous silicon. Appl. Phys. Lett., 88, 171907. http://dx.doi.org/+10.1063/1.2199593.

Myers, R. A., Farrell, R., Karger, A. M., Carey, J. E., \& Mazur, E. (2006). Enhancing near-infrared avalanche photodiode performance by femtosecond laser microstructuring. Applied Optics, 45, 8825-8831. http://dx.doi.org/ 10.1364/AO.45.008825

Nesheva, D., Raptis, C., Perakis A., Bineva I., Aneva, Z., Levi, Z., Alexandrova, S., \& Hofmeister, H. (2002). Raman scattering and photoluminescence from Si nanoparticles in annealed $\mathrm{SiO}_{\mathrm{x}}$ thin films. J. Appl. Phys., 92, 4678-4683. http://dx.doi.org/10.1063/1.1504176

Nishioka, K., Horita. S., Ohdaira, K., \& Matsumura, H. (2008). Antireflection subwavelength structure of silicon surface formed by wet process using catalysis of single nano-sized gold particle. Solar Energy Materials and Solar Cells, 92, 919-922. http://dx.doi.org/10.1016/j.solmat.2008.02.017

Noval, A. M., Costa, V. S., Gallach. D, Silvan, M. M, Ruiz, J. P. G, Perez, M. H., ... R. J. M. (2011). Silicon-based hybrid luminescent/magnetic porous nanoparticles for biomedical applications. $J$. Nanophoton, 5, 051505. http://dx.doi.org/10.1117/1.3549739

Othonos, A., Zervos, M., \& Pervolaraki, M. (2009). Ultrafast Carrier Relaxation in InN Nanowires Grown by Reactive Vapor Transport. Nanoscale Res Lett., 4, 122-129. http://dx.doi.org/10.1007/s11671-008-9211-8

Reurings, F., Rauch, C., Tuomisto, F., Jones, R. E., Yu, K. M., Walukiewicz, W., \& Schaff, W. J. (2010). Defect redistribution in postirradiation rapid-thermal-annealed InN. Phys. Rev. B., 82, 3202-3205. http://dx.doi.org/10.1103/PhysRevB.82.153202 
Sheehy, M. A., Winston, L., Carey, J. E., Friend, C. M., \& Mazur, E. (2005). Role of the Background Gas in the Morphology and Optical Properties of Laser-Microstructured Silicon. Chem. Mater., 17, 3582-3586. http://dx.doi.org/10.1021/cm049029i

Tezcan, D. S., Eminoglu, S., \& Akin, T. (2003). A low-cost uncooled infrared microbolometer detector in standard CMOS technology. IEEE Trans. Electron Devices, 50, 494-502. http://dx.doi.org/10.1109/TED.2002.807453

Trakhtenberg, L. I., Gerasimov, G. N., Gromov, V. F., Belysheva, T. V., \& Ilegbusi, O. J. (2012). Gas Semiconducting Sensors Based on Metal Oxide Nanocomposites. Journal of Materials Science Research, I(2), 56-68. http://dx.doi.org/ 10.5539/jmsr.v1n2p56

Treado, P. J., Levin, I. W., \& Lewis, E. N. (1994). Indium antimonide (InSb) focal plane array (FPA) detection

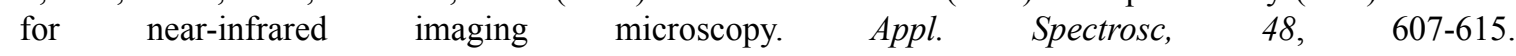
http://dx.doi.org/0003-7028/94/4805-0607

Wu, C., Crouch, C. H., Zhao, L., Carey. J. E., Younkin, R., Levinson, J. A., ... Karger, A. (2001). Near-unity below-band-gap absorption by microstructured silicon. Appl. Phys. Lett., 78, 1850-1852. http://dx.doi.org/10.1063/1.1358846

Younkin, R., Carey, J. E., Mazur, E., \& Friend, C. M. (2003). Infrared absorption by conical silicon microstructures made in a variety of background gases using femtosecond-laser pulses. J. Appl. Phys., 93, 2626-2629. http://dx.doi.org/+10.1063/1.1545159.

Yuan, H. C., Yost, V. E., Page, M. R., Stradins, P., Meier, D. L., \& Branz, H. M. (2009). Efficient black silicon solar cell with a density-graded nanoporous surface: Optical properties, performance limitations, and design rules. Appl. Phys. Lett., 95, 123501. http://dx.doi.org/+10.1063/1.3231438.

Zacharias, M., Blasing, J., Veit, P., Tsybeskov, L., Hirschman, K., \& Fauchet, P. M. (1999). Thermal crystallization of amorphous $\mathrm{Si}_{/} \mathrm{SiO}_{2}$ superlattices. Appl. Phys. Lett., 74, 2614-2616. http://dx.doi.org/10.1063/1.123914 